\title{
Corrosion Performance of Poorly Pickled Stainless Steel Reinforcement
}

\author{
by M. O'Reilly, J. Sperry, D. Darwin, J. Lafikes, I. Somogie, S. Storm, and J. Browning
}

\begin{abstract}
XM-28 (UNS S24100) and 2304 (UNS S32304) stainless steel reinforcing bars with different levels of pickling were evaluated for corrosion resistance using the rapid macrocell and cracked beam tests outlined in ASTM A955. Two heats of XM-28 from the same producer were evaluated using the rapid macrocell test. A single heat of 2304 was evaluated in two conditions; as-received from the manufacturer and re-pickled using both ASTM A955 tests. The poorly pickled heat of XM-28 reinforcement failed the rapid macrocell test with a peak individual corrosion rate exceeding $16 \mu \mathrm{m} / \mathrm{y}$, while the properly pickled heat passed with no significant corrosion measured. The poorly pickled 2304 reinforcing steel failed the macrocell and cracked beam tests, with peak corrosion rates of 1.07 and $6.48 \mu \mathrm{m} / y$, respectively, while upon re-pickling, the same heat of steel passed both tests. These results suggest the need for a method to verify that the pickling process has been performed properly. Performance during the first week of the rapid macrocell tests or requiring that the bars exhibit a bright, shiny, uniformly light surface represent two potential methods for establishing the adequacy of pickling.
\end{abstract}

Keywords: chlorides; corrosion; microcell; pickling; stainless steel.

\section{INTRODUCTION}

Chloride-induced corrosion is a threat to the resiliency of reinforced concrete structural members exposed to marine environments or deicing salts. A 2002 study placed the annual direct cost of corrosion damage to highway bridges at $\$ 8.3$ billion; including all infrastructure, the annual cost rises to $\$ 22.6$ billion (Koch et al. 2002). These costs are only rising with time, and the current budget for maintenance is not increasing congruently with these expenses. The American Society of Civil Engineers gave the current state of America's infrastructure a $\mathrm{D}+$ rating in their annual report card (ASCE 2013a) and predicts a maintenance shortfall of over $\$ 1$ trillion by 2020 (ASCE 2013b).

With the rising costs of maintenance, improving the time to first repair for reinforced concrete structures has become an increasingly important focus for structural engineers. This issue is of particular importance in marine environments and in structural members exposed to deicing salts, where chlorides penetrate the concrete and corrode reinforcement, eventually leading to cracking and spalling of the concrete. One method of improving corrosion resistance for structures in chloride-exposed environments is the use of stainless steel reinforcement (Smith and Tullmin 2007). Numerous stainless steel alloys have been used as reinforcement. In general, stainless steel reinforcement has a chloride threshold (the concentration of chlorides in the concrete required to initiate corrosion) several times greater than that of conventional reinforcement (Trejo and Pillai 2004; Darwin et al. 2013) as well as a significantly lower corrosion rate after initiation (McDonald et al. 1995).

The combination of a high chloride threshold and a low corrosion rate has made stainless steel reinforcement an attractive choice for use in environments with severe chloride exposure. The strong corrosion resistance of stainless steel, however, is dependent on the surface condition of the bars. Stainless steel reinforcement achieves its corrosion resistance through the formation of a thin chromium oxide passive layer on the surface of the bar (Jones 1996). Stainless steel producers typically accomplish this by submerging the bar in an acid solution, a process known as pickling. Pickling cleans the bar, removing mill scale and encouraging the formation of the passive layer. If the pickling process is not performed, the reinforcement exhibits significantly reduced corrosion resistance ( $\mathrm{Ji}$ et al. 2005). As such, nearly all stainless steel reinforcement is sold in a pickled state.

The stability of the passive layer, however, is sensitive to many details of the pickling process, such as the time of exposure to the acid solution, solution temperature, and acid concentration. If the exposure time is too short or the concentration of acid is too low, the passive layer will either form incompletely or not form at all, providing limited protection to the steel. Excessive exposure can cause over-pickling, which impairs the corrosion resistance by damaging the surface of the metal. Given the high initial cost of stainless steel reinforcement, it is critical that the prevalence of improperly pickled stainless steel reinforcement and the magnitude of the impacts of the improper pickling be established so that it is possible to design cost-effective structures with long service lives.

\section{RESEARCH SIGNIFICANCE}

Corrosion is an increasingly costly challenge. Engineers are using stainless steel reinforcement in increasing quantities, taking advantage of its high corrosion resistance to achieve a longer service life than would be obtained with conventional reinforcement. However, the high corrosion resistance of many alloys of stainless steel requires that the pickling process be performed correctly such that a strong passive layer forms on the steel. This study demonstrates that this process is not always performed properly and illus-

ACI Materials Journal, V. 114, No. 6, November-December 2017.

MS No. M-2015-367.R2, doi: 10.14359/51701008, was received July 6, 2016, and reviewed under Institute publication policies. Copyright (C) 2017, American Concrete Institute. All rights reserved, including the making of copies unless permission is obtained from the copyright proprietors. Pertinent discussion including author's closure, if any, will be published ten months from this journal's date if the discussion is received within four months of the paper's print publication. 
Table 1-Chemical compositions of steels evaluated in this study

\begin{tabular}{c|c|c|c|c|c|c|c|c|c|c|c|c|c}
\hline Material & UNS & $\mathrm{B}$ & $\mathrm{C}$ & $\mathrm{Co}$ & $\mathrm{Cr}$ & $\mathrm{Cu}$ & $\mathrm{Mn}$ & $\mathrm{Mo}$ & $\mathrm{N}$ & $\mathrm{Ni}$ & $\mathrm{P}$ & $\mathrm{S}$ & $\mathrm{Si}$ \\
\hline $\mathrm{XM}-28(1)^{*}$ & 24100 & 0.0023 & 0.05 & 0.06 & 17.5 & 0.05 & 12.1 & 0.25 & 0.26 & 0.81 & 0.019 & $<0.001$ & 0.28 \\
\hline $\mathrm{XM}-28(2)^{\dagger}$ & 24100 & 0.0022 & 0.05 & 0.03 & 17.8 & 0.07 & 12.2 & 0.18 & 0.29 & 0.74 & 0.019 & 0.001 & 0.29 \\
\hline 2304 & 32304 & 0.002 & 0.02 & - & 22.71 & 0.3 & 1.72 & 0.25 & 0.18 & 3.58 & 0.02 & 0.001 & 0.41 \\
\hline
\end{tabular}

*First heat.

†Second heat.

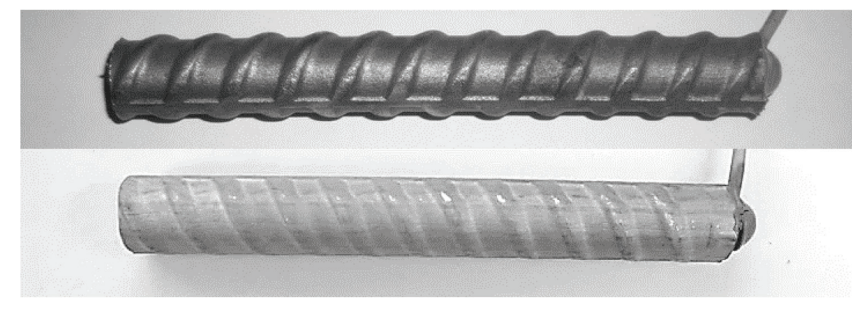

Fig. 1-XM-28(1) first heat (top) and XM-28(2) second heat (bottom). No. 16 (No. 5) bars.

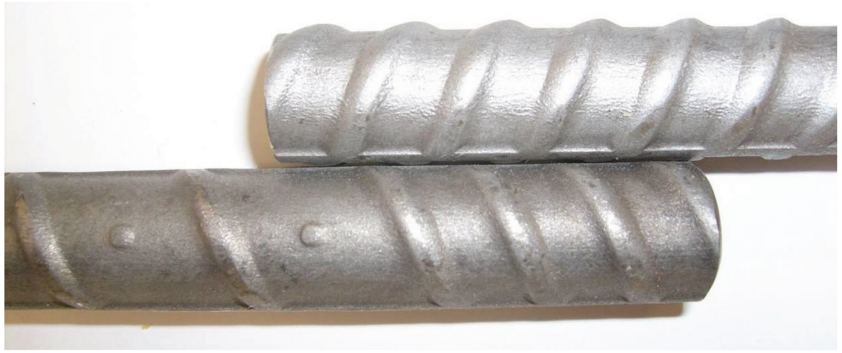

Fig. 2-2304 as-received (left) and re-pickled (right). No. 16 (No. 5) bars.

trates the impact that improper pickling has on the corrosion resistance of two stainless steel alloys.

\section{Materials}

\section{EXPERIMENTAL WORK}

Two types of stainless steels were evaluated in this study, consisting of two heats of XM-28 austenitic stainless steel (UNS S24100) and a single heat of 2304 duplex stainless steel (UNS S32304). The chemical compositions of these steels are provided in Table 1. Further details of the tests of the 2304 reinforcement are presented by Darwin et al. (2013).

Both steels were pickled by the producers. The samples from the two heats of XM-28 steel are shown in Fig. 1. The first heat, identified as XM-28(1), had a dark, mottled appearance, while the second heat had a uniformly light surface finish. The single heat of 2304 stainless steel was tested in two conditions: as received and re-pickled by the authors. The re-pickling process consisted of submerging the bars in a solution of $25 \%$ nitric acid and $5 \%$ hydrofluoric acid at room temperature $\left(22^{\circ} \mathrm{C}\left[72^{\circ} \mathrm{F}\right]\right)$ for 30 minutes, followed by rinsing the bars with distilled water. The 2304 bars before and after re-pickling is shown in Fig. 2. In the two heats of XM-28 steel shown in Fig. 1, the as-received 2304 had a dark, mottled appearance and the re-pickled 2304 had a bright, shiny appearance.

\section{Test procedures}

The XM-28 and 2304 stainless steels were evaluated using the rapid macrocell test. In addition, the 2304 stainless steel

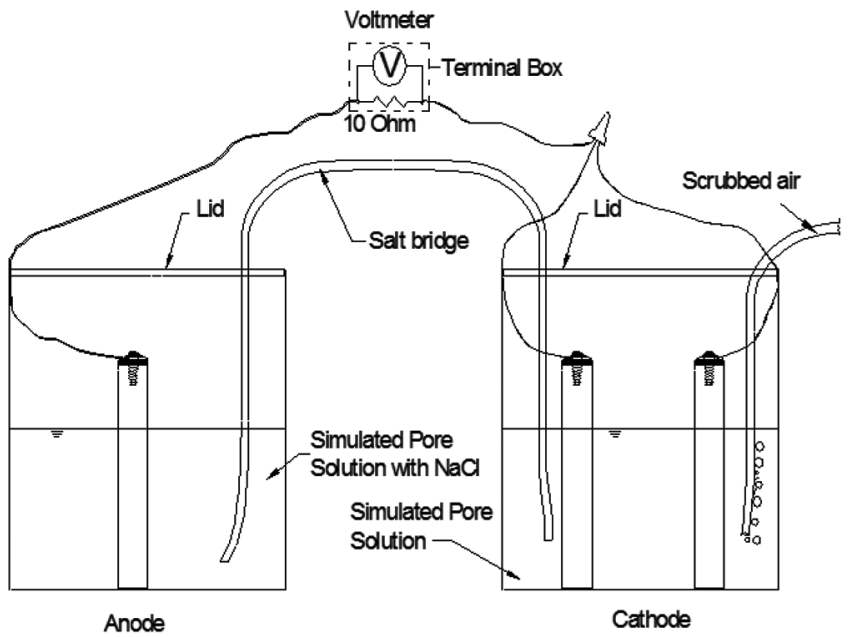

Fig. 3-Rapid macrocell test specimen.

was evaluated using the cracked beam test. Both test procedures are outlined as follows; full details of the tests are given in O'Reilly et al. (2011) and in Annexes A.1 through A.3 of ASTM A955 (2015).

Rapid macrocell test-Rapid macrocell specimens (Fig. 3) consist of a single $127 \mathrm{~mm}$ (5 in.) long No. 16 (No. 5) reinforcing bar in a container with simulated concrete pore solution containing salt and two $127 \mathrm{~mm}$ (5 in.) long No. 16 (No. 5) reinforcing bars in a second container with simulated pore solution not containing salt. One liter of pore solution contained $18.81 \mathrm{~g}$ potassium hydroxide, $17.87 \mathrm{~g}$ sodium hydroxide, and $974.8 \mathrm{~g}$ distilled water. 174.1 g sodium chloride was added to $1 \mathrm{~L}$ of pore solution to create the salt solution at the anode. The containers are filled to a depth of $76 \mathrm{~mm}$ ( $3 \mathrm{in}$.) with their respective pore solutions, and air scrubbed to remove $\mathrm{CO}_{2}$ is bubbled to the pore solution in the second container to provide oxygen. The bars in the two containers are connected ionically via a potassium chloride salt bridge, and electrically across a $10-\mathrm{ohm}$ resistor to allow for corrosion rate measurements to be taken. By measuring the voltage drop across the 10 -ohm resistor, the current flow to the anode may be determined, which in turn can be expressed as a current density $i$ in microamps per square centimeter $\left(\mu \mathrm{A} / \mathrm{cm}^{2}\right)$ based on the anode surface area. Faraday's law can be used to convert current density $i$ to the rate of metal loss $R(\mu \mathrm{m} / \mathrm{y})$ based on the atomic weight of the metal $a(55.8 \mathrm{~g} / \mathrm{mole}$ for iron $)$, the number of electrons transferred $n$ ( 2 for iron), Faraday's constant $F$ ( 96,500 Coulombs/ equivalent) and the metal density $\rho\left(7.87 \mathrm{~g} / \mathrm{cm}^{3}\right.$ for iron) (Jones 1996). 


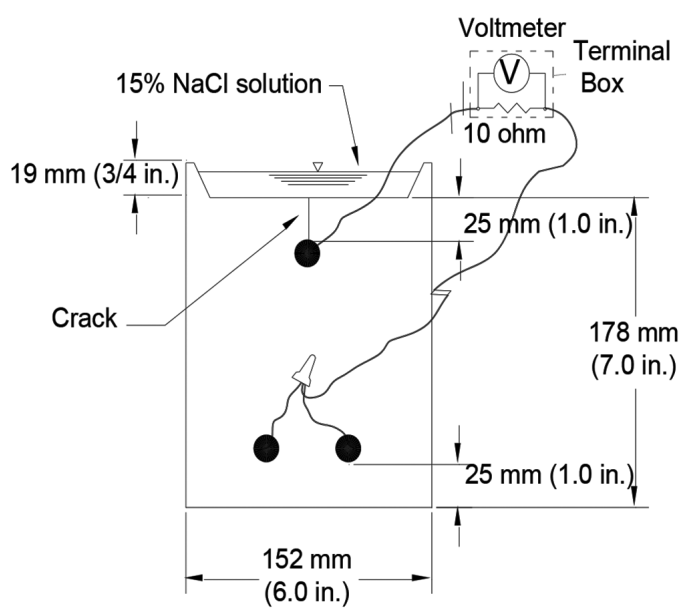

Fig. 4-Cracked beam specimen.

In Eq. (1), $k$ is a conversion factor $=31.5 \times 10^{4} \mathrm{amp} \cdot \mathrm{m}$ $\mathrm{s} / \mu \mathrm{A} \mathrm{cm} \cdot \mathrm{y}$.

For the rapid macrocell test, measurements are taken daily for the first week and weekly thereafter. The test duration is 15 weeks; the solutions are changed at 5-week intervals.

Cracked beam test-Cracked beam specimens (Fig. 4) consist of two mats of No. 16 (No. 5) reinforcement with $25 \mathrm{~mm}$ ( 1 in.) clear cover, cast in a $152 \times 305 \times 178 \mathrm{~mm}(6 \times 12$ $\mathrm{x} 7$ in.) concrete block. The top mat contains a single No. 16 (No. 5) bar; the bottom mat contains two bars. The bars in the top and bottom mats are electrically connected via external wiring to a terminal box across a 10-ohm resistor to allow for corrosion rate measurements. The specimens are cast upside down with a $0.3 \mathrm{~mm}(12 \mathrm{mil}) \times 152 \mathrm{~mm}(6 \mathrm{in}$.) stainless steel shim placed in the mold in contact with the top bar prior to casting. This shim is removed 12 hours after casting, leaving a $152 \mathrm{~mm}$ (6 in.) long crack in the concrete over the top bar. A $19 \mathrm{~mm}(0.75 \mathrm{in}$.) concrete dam is cast integrally with the top of the specimen to allow for ponding of saltwater.

For the cracked beam test, measurements are taken weekly. The test lasts 96 weeks with alternating 12-week cycles (ASTM A955 only considers test results through week 75). During the first cycle, specimens are ponded for 4 days with a $15 \%$ salt solution at room temperature, 20 to $24^{\circ} \mathrm{C}$ (68 to $\left.76^{\circ} \mathrm{F}\right)$. The solution is vacuumed off and the specimens are placed under a heat tent at $38^{\circ} \mathrm{C}\left(100^{\circ} \mathrm{F}\right)$ for 3 days, completing 1 week of testing. This procedure is repeated through 12 weeks, completing the first cycle. The specimens then enter a second 12-week cycle, during which they are kept continuously ponded with salt solution at room temperature. The two cycles are alternated for the duration of the test.

ASTM A955 limits-ASTM A955 qualifies stainless steels for corrosion resistance using rate limits on the two tests outlined previously. A minimum of five specimens are required. For the rapid macrocell test, no specimen can exhibit a corrosion rate greater than $0.5 \mu \mathrm{m} / \mathrm{y}$ at any point during the test, and the average rate must remain below $0.25 \mu \mathrm{m} / \mathrm{y}$ at all times. For the cracked beam test, no specimen can exhibit a corrosion rate greater than $0.5 \mu \mathrm{m} / \mathrm{y}$ at any point, and the average rate must remain below $0.2 \mu \mathrm{m} / \mathrm{y}$.

\section{Test program}

In this study, specimens from two heats of XM-28 were evaluated using the rapid macrocell test, with six specimens per heat. As-received and re-pickled 2304 were evaluated using both the rapid macrocell and cracked beam tests, with six specimens per condition in each test.

\section{XM-28 stainless steel}

\section{RESULTS}

Rapid macrocell test-Individual corrosion rates from the rapid macrocell test for specimens from XM-28(1) (poorly pickled) and XM(2) (properly pickled) are shown in Fig. 5(a) and (b), respectively. Figure 5(c) shows individual corrosion rates for XM-28(1) with an expanded scale. The dashed horizontal line represents the ASTM A955 corrosion rate limit for individual specimens of $0.5 \mu \mathrm{m} / \mathrm{y}$. For the poorly pickled XM-28(1) (Fig. 5(a)), all six specimens exceeded the $0.5 \mu \mathrm{m} / \mathrm{y}$ limit, with a peak corrosion rate of $16.4 \mu \mathrm{m} / \mathrm{y}$ observed for Specimen XM28(1)-3 at week 5. No specimen of XM-28(2) exhibited a measurable positive corrosion rate at any point during the test (Fig. 5(b)). The "negative" corrosion rates observed in the figures are the result of a slight current drift between anode and cathode and are not indicative of corrosion, nor are they a cause to disqualify stainless steel under ASTM A955.

Photos of the poorly and properly pickled XM-28 steel after testing are shown in Fig. 6(a) and (b), respectively. The top bar in each photo is the anode bar; the two bottom bars are cathode bars. After testing, all anode bars from the poorly pickled steel showed visible signs of corrosion, particularly at and above the level of pore solution in the container (Fig. 6(a)). The cathode bars showed no visible corrosion. For the properly pickled steel, no corrosion products were visible on any of the anode or cathode bars (Fig. 6(b)).

\section{4 stainless steel}

Rapid macrocell test -Figures 7(a) and (b) show individual corrosion rates from the rapid macrocell test for the 2304 stainless steel in, respectively, the as-received and re-pickled conditions. For the as-received 2304 (Fig. 7(a)), three out of the six specimens exceeded the $0.5 \mu \mathrm{m} / \mathrm{y}$ corrosion rate limit: Specimen 2304-1 at weeks 4 and 5, Specimen 2304-2 at week 11, and Specimen 2304-3 at week 4. The maximum individual corrosion rate, $1.07 \mu \mathrm{m} / \mathrm{y}$, was observed for Specimen 2304-1 at week 5. For the re-pickled 2304 (Fig. 7(b)), no specimen exceeded the $0.5 \mu \mathrm{m} / \mathrm{y}$ limit. The maximum individual corrosion rate, $0.145 \mu \mathrm{m} / \mathrm{y}$, was observed on Specimen 2304-p-2 during the first week of testing.

Photos of the as-received and re-pickled 2304 specimens after testing are shown in Fig. 8(a) and (b), respectively. The top bar in each photo is the anode bar; the two bottom bars are cathode bars. No corrosion products were visible on any of the anode or cathode bars in either condition, although the as-received bars (Fig. 8(a)) generally had a darker appearance than the re-pickled bars (Fig. 8(b)).

Cracked beam test-The individual corrosion rates from the cracked beam test for the 2304 stainless steel are shown in Fig. 9(a) and (b) for the as-received and re-pickled conditions, respectively. Figure 9(c) shows individual corrosion 


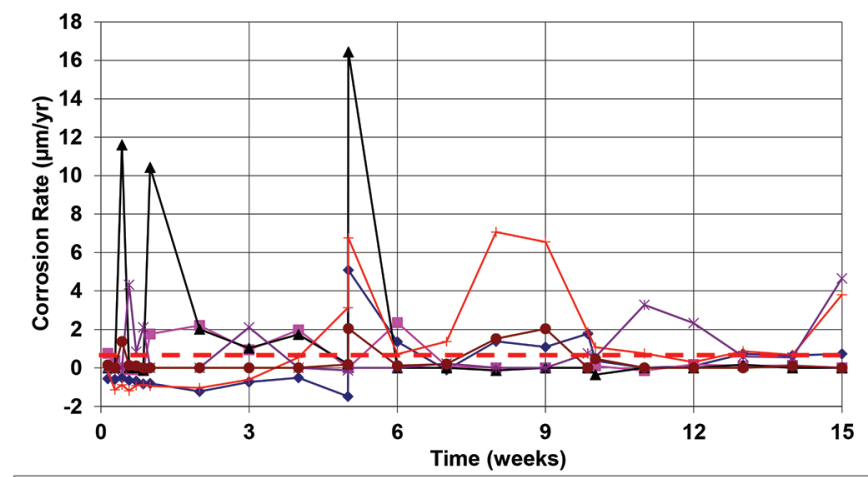

$\leftarrow \mathrm{XM} 28(1)-1 \rightarrow \mathrm{XM} 28(1)-2 \multimap \mathrm{XM} 28(1)-3 \multimap \mathrm{XM} 28(1)-4 \rightarrow \mathrm{XM} 28(1)-5 \multimap \mathrm{XM} 28(1)-6$

(a)
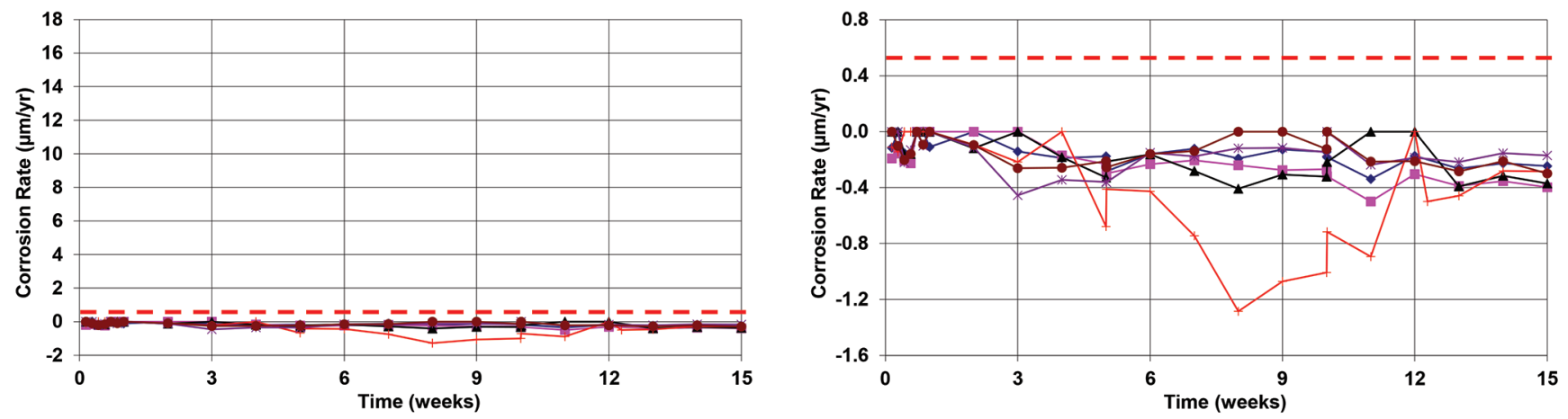

$\rightarrow \mathrm{XM} 28(2)-1 \rightarrow \mathrm{XM} 28(2)-2 \rightarrow \mathrm{XM} 28(2)-3 \multimap \mathrm{XM} 28(2)-4 \rightarrow \mathrm{XM} 28(2)-5 \rightarrow \mathrm{XM} 28(2)-6$

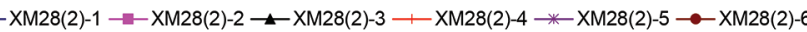

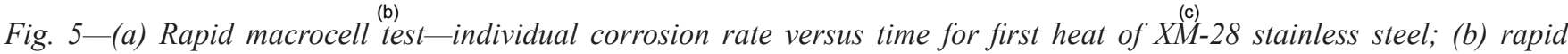
macrocell test-individual corrosion rate versus time for second heat of XM-28 stainless steel; and (c) rapid macrocell testindividual corrosion rate versus time for second heat of XM-28 stainless steel (different scale).

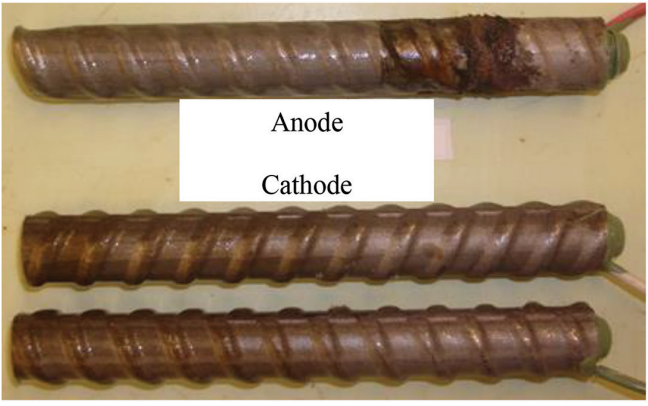

(a)

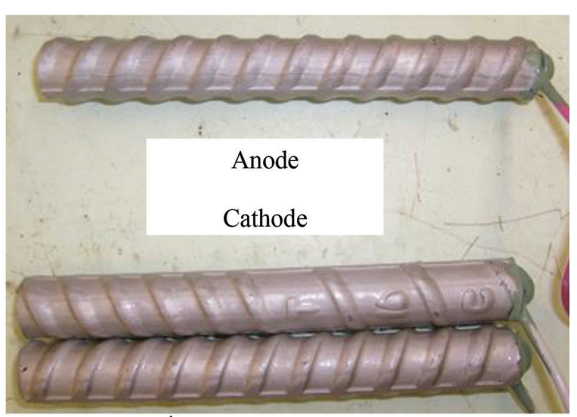

(b)

Fig. 6-(a) Rapid macrocell test-first heat specimen XM28(1)-6 after testing. Anode bar (top) and cathode bars (bottom). No. 16 (No. 5) bars; and (b) rapid macrocell test-second heat specimen XM28(2)-4 after testing. Anode bar (top) and cathode bars (bottom). No. 16 (No. 5) bars.

rates for the re-pickled 2304 on an expanded scale. For the as-received 2304 (Fig. 9(a)), Specimen CB-2304-2 exceeded the $0.5 \mu \mathrm{m} / \mathrm{y}$ limit at week 4, and Specimen CB-2304-1 exceeded the limit at week 12 . The corrosion rate for all specimens remained below $1.0 \mu \mathrm{m} / \mathrm{y}$ through week 36 , when the corrosion rate began to increase for Specimens CB-2304-2 and CB-2304-3. By week 75, all six specimens had exceeded the $0.5 \mu \mathrm{m} / \mathrm{y}$ limit. The peak corrosion rate during the first 75 weeks was $5.51 \mu \mathrm{m} / \mathrm{y}$ for Specimen 2304-5 at week 66; through 96 weeks, the peak rate was $6.48 \mu \mathrm{m} / \mathrm{y}$ for Specimen 2304-1 at week 94. For the re-pickled 2304 (Fig. 9(b)), specimens had corrosion rates less than $0.1 \mu \mathrm{m} / \mathrm{y}$ for most of the test, with a few isolated spikes above $0.1 \mu \mathrm{m} / \mathrm{y}$. The peak corrosion rate was $0.159 \mu \mathrm{m} / \mathrm{y}$ for Specimen CB-2304-p-6 at week 45; no specimen exceeded the $0.5 \mu \mathrm{m} / \mathrm{y}$ limit.

Photos of the as-received 2304, a closeup of the corrosion on the top bar of the as-received 2304, and the re-pickled 2304 after testing are shown in Fig. 10(a) through (c), respectively. The top bars in Fig. 10(a) and (c) are the anode bars (as is the bar shown in Fig. 10(b)); the bottom two bars are cathode bars. All the as-received bars showed moderate corrosion in the area of the bar under the crack, as shown in Fig. 10(a) and (b), with no corrosion on the bottom bars. No corrosion was observed on any of the re-pickled 2304 bars (Fig. 10(c)). 


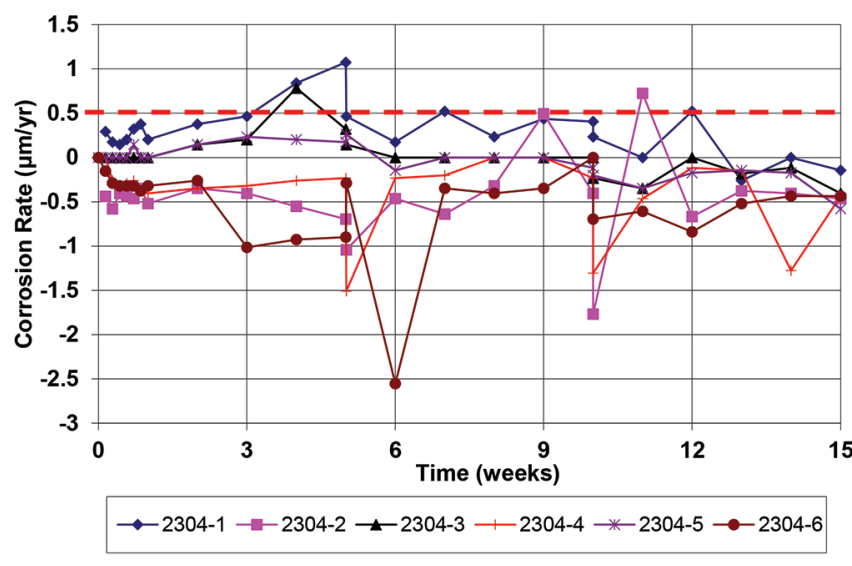

(a)

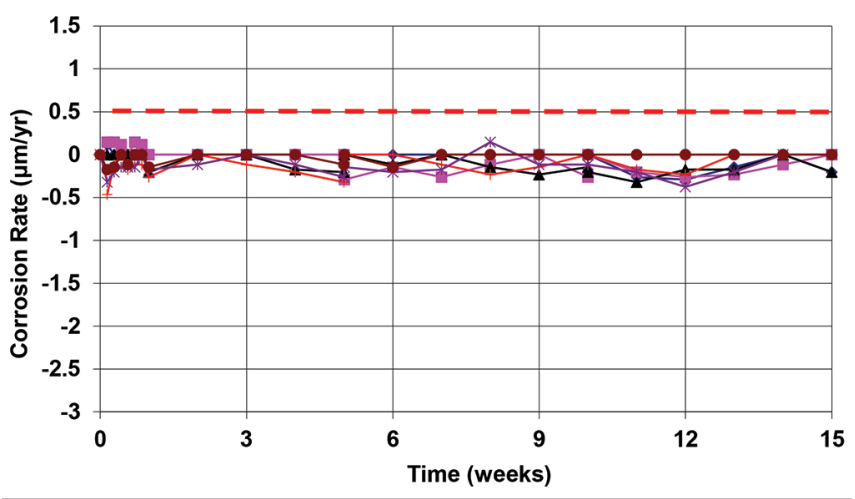

$\longrightarrow 2304-p-1 \rightarrow-2304-p-2 \rightarrow 2304-p-3 \longrightarrow 2304-p-4 \rightarrow 2304-p-5 \rightarrow 2304-p-6$

(b)

Fig. 7-(a) Rapid macrocell test-individual corrosion rate versus time for 2304 stainless steel in the as-received condition; and (b) rapid macrocell test-individual corrosion rate versus time for 2304 stainless steel in the re-pickled condition.

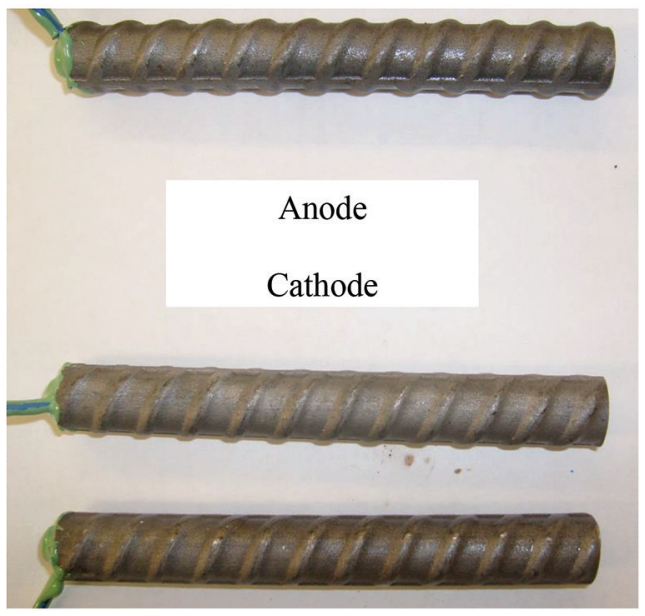

(a)

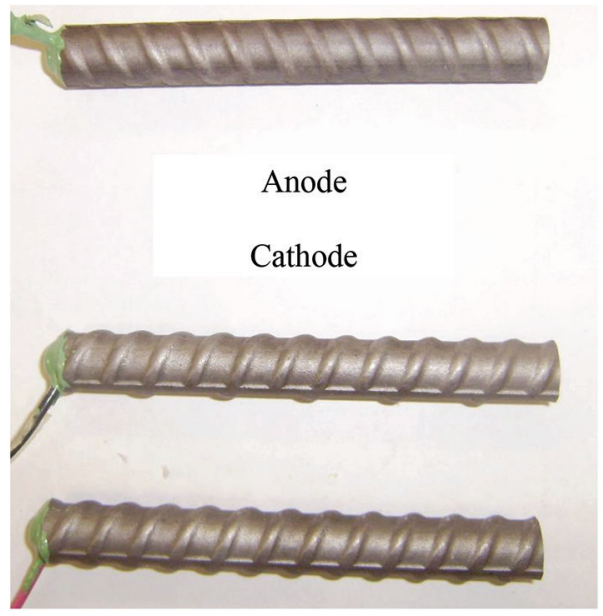

(b)

Fig. 8-(a) Rapid macrocell test of as-received Specimen 2304-1 after testing. Anode bar (top) and cathode bars (bottom). No. 16 (No. 5) bars; and (b) rapid macrocell test of re-pickled Specimen 2304-p-4 after testing. Anode bar (top) and cathode bars (bottom). No. 16 (No. 5) bars.

\section{DISCUSSION}

Both XM-28 and 2304 stainless steel performed very well when pickled to a bright, shiny, or uniformly light finish but poorly when pickled to a duller finish. For the 2304 stainless steel, the only difference between the specimens that passed the ASTM A955 corrosion rate tests and those that did not was the second pickling performed by the authors, indicating the first pickling process, undertaken by the producer, was not sufficient to passivate the steel. For XM-28, two different heats were tested, introducing the additional variable of the chemical composition of the steels. The steel chemistries of the two heats, however, were similar (Table 1), and the difference in finish again suggests an issue with the pickling process on the first heat. It is important to note that the two poorly performing steels in this study (XM-28(1) and the as-received 2304) were not intentionally left in a poorly pickled state for research; the first heat of XM-28 was sent for qualification by a producer and the 2304 was obtained for study from a previously qualified producer. This suggests that the pickling process is not being performed in a consistent manner; thus, either a rapid method for determining the corrosion resistance of stainless steel or an alternate criterion for acceptance is needed on a heat-by-heat basis.

The qualification standards for corrosion resistance outlined in ASTM A955 need only be met once by a producer for a given type of stainless steel; subsequent heats are not required to be tested under Annexes A.1 through A.3 of ASTM A955. Although the rapid macrocell and cracked beam tests are effective at determining the corrosion resistance of stainless steels, the test durations of 15 and 75 weeks, respectively, make them impractical for use on every heat of stainless steel produced. The authors continue to investigate this problem and encourage further research toward establishing a rapid evaluation method. In the interim, the surface finish on the steel can serve as a visual indicator of corrosion resistance with a bright, shiny, or uniformly light surface being correlated with satisfactory corrosion resistance for the steels in this study. Ensuring the pickling process is carried out in a proper manner (ensuring proper concentration of acid, solution temperature, and exposure time) can help to achieve this goal. 


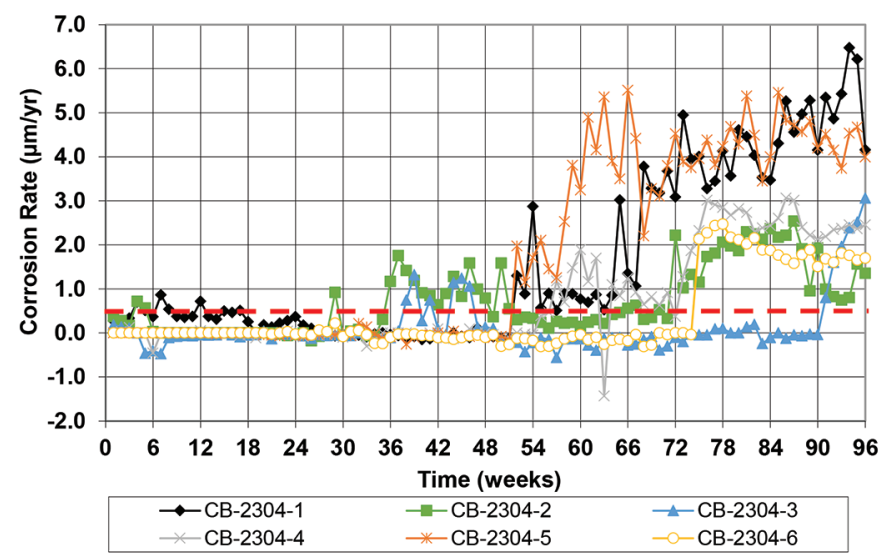

(a)

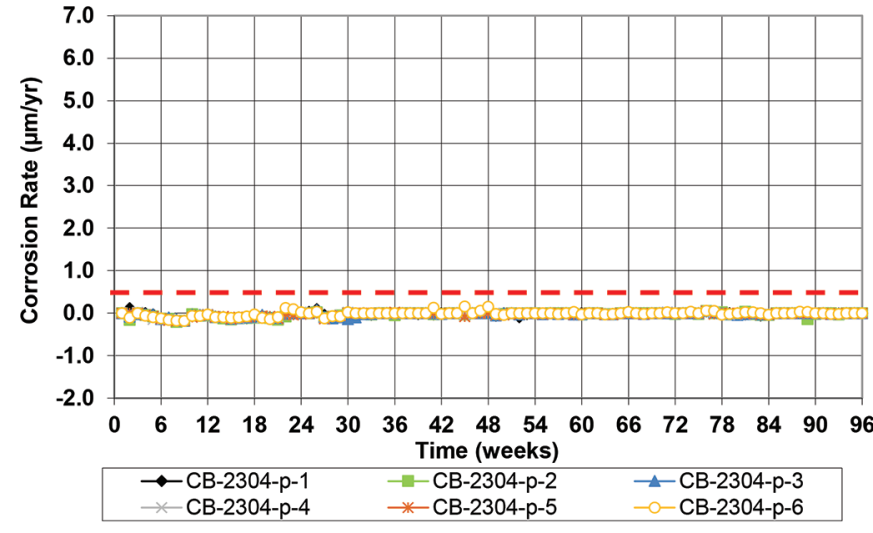

(b)

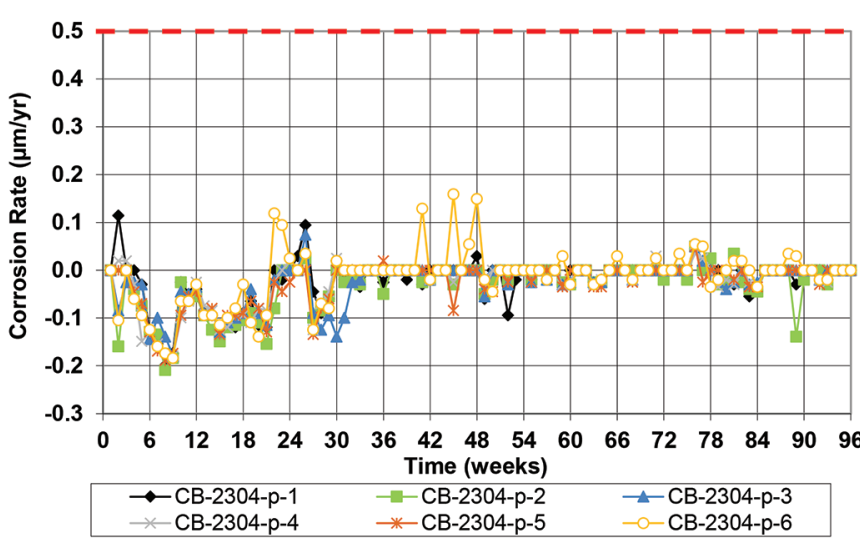

(c)

Fig. 9-(a) Cracked beam test-individual corrosion rate versus time for 2304 stainless steel in the as-received condition; (b) cracked beam test-individual corrosion rate versus time for 2304 stainless steel in the re-pickled condition; and (c) cracked beam test-individual corrosion rate versus time for 2304 stainless steel in the re-pickled condition (different scale).

The evaluation of the 2304 stainless steel in both the rapid macrocell and cracked beam tests provides an opportunity to compare the sensitivity of the two tests. The 2304 in the as-received condition failed the rapid macrocell test by a comparatively small margin (two specimens exceeded the $0.5 \mu \mathrm{m} / \mathrm{y}$ limit for 1 week, with a third exceeding the limit twice). Similar behavior was seen in the first 36 weeks of the cracked beam test for the as-received 2304; performance in the cracked beam test, however, clearly worsened as the test continued (Fig. 9(a)). This indicates that the rapid macrocell test may be useful as a relatively quick means for determining if a stainless steel has reduced corrosion resistance, but it cannot be directly correlated to long-term corrosion rates in concrete.

\section{SUMMARY AND CONCLUSIONS}

Samples from two of XM-28 austenitic stainless steel (UNS S24100) and one heat of 2304 duplex stainless steel (UNS S32304) were evaluated for corrosion resistance using the rapid macrocell and cracked beam tests specified in Annexes A.1 through A.3 of ASTM A955. As received, one heat of XM-28 and the single heat of 2304 steel had a dull appearance, suggesting an improper pickling process. The second heat of XM-28 was obtained from the same producer but had a uniformly light surface finish; samples of the 2304 steel were re-pickled by the authors to a shiny, bright condition. Both heats of XM-28 and the 2304 in the as-received and re-pickled conditions were evaluated using the rapid macrocell test for 15 weeks; the 2304 steel was also evaluated using the cracked beam test for 96 weeks.

The following conclusions are based on the results and analyses presented in this paper:

1. Some stainless steel reinforcement is being produced and sold with poor pickling, leading to reduced corrosion resistance. The steels tested, however, exhibited a high resistance to corrosion when the pickling process was properly performed. Steps should be taken during production to ensure adequate pickling.

2. A method is needed to evaluate the formation of a strong passive layer for individual heats of stainless steel reinforcement. The test methods specified in ASTM A955 are too time consuming to be applied in their entirety to every heat of steel, but poor performance during the first week of the rapid macrocell test may provide a relatively rapid indication of corrosion resistance.

3. A bright, shiny, or uniformly light surface correlated well with satisfactory corrosion resistance for the stainless steels evaluated in this study. A requirement on surface appearance could thus be applied to individual heats of a stainless steel that has been previously qualified under the provisions of Annexes A.1 through A.3 of ASTM A955. 


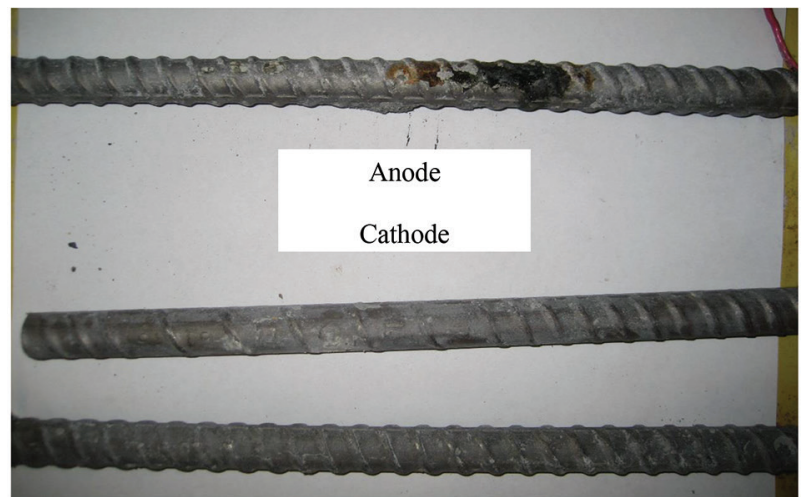

(a)

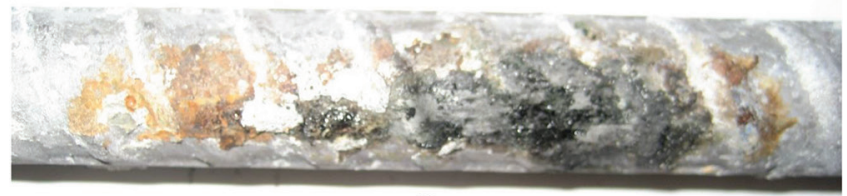

(b)

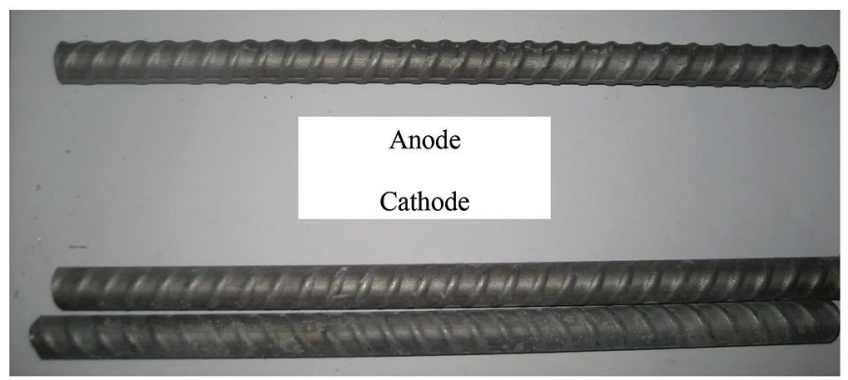

(c)

Fig. 10-(a) Cracked beam test of as-received Specimen CB-2304-1 after testing. Anode bar (top) and cathode bars (bottom). No. 16 (No. 5) bars; (b) cracked beam test of asreceived Specimen CB-2304-1 after testing. Closeup of corrosion on anode bar. No. 16 (No. 5) bar; and (c) cracked beam test of re-pickled Specimen CB-2304-p-1 after testing. Anode bar (top) and cathode bars (bottom). No. 16 (No. 5) bars.

\section{AUTHOR BIOS}

ACI member Matthew O'Reilly is an Assistant Professor of civil, environmental, and architectural engineering at the University of Kansas, Lawrence, KS. He received his BS in mechanical engineering from the University of Rochester, Rochester, NY, and his MS and PhD degrees in civil engineering from the University of Kansas. He is a member of ACI Committees 123, Research and Current Developments, and 222, Corrosion of Metals in Concrete.

ACI member Jayne Sperry is a PhD Student in civil engineering at the University of Kansas, where she also received her BS and MS degrees in civil engineering.

ACI Honorary Member David Darwin is the Deane E. Ackers Distinguished Professor and Chair of the Department of Civil, Environmental, and Architectural Engineering at the University of Kansas and a Past President of ACI. He is a member of ACI Committees 222, Corrosion of Metals in Concrete; 224, Cracking; ACI Subcommittee 318-B, Anchorage and Reinforcement (Structural Concrete Building Code); and Joint ACI-ASCE
Committees 408, Bond and Development of Steel Reinforcement; 445, Shear and Torsion; and 446, Fracture Mechanics of Concrete.

ACI member James Lafikes is a PhD Student in civil engineering at the University of Kansas. He received his BS in civil engineering from the University of Missouri-St. Louis/Washington University Joint Undergraduate Engineering Program and his MS in civil engineering from the University of Kansas. He is a member of ACI Committees 222, Corrosion of Metals in Concrete, and 563, Specifications for Repair of Structural Concrete in Buildings.

Isaac Somogie is a Structural Engineer at BlueScope Construction. He received his BS in civil engineering from the University of Missouri-Kansas City, Kansas City, MO, and his MS in civil engineering from the University of Kansas.

Scott Storm is a Senior Engineer at Thornton Tomasetti. He received his $B S$ and MS in civil engineering from the University of Kansas.

JoAnn Browning, FACI, is the Dean of the School of Engineering and David and Jennifer Spencer Distinguished Chair at the University of Texas at San Antonio, San Antonio, TX, and a member of the ACI Board of Direction. She is a member of the ACI Technical Activities Committee and ACI Committees 314, Simplified Design of Concrete Buildings; 318, Structural Concrete Building Code; 341, Earthquake-Resistant Concrete Bridges; 374, Performance-Based Seismic Design of Concrete Buildings; and Joint ACI-ASCE Committee 408, Bond and Development of Reinforcement.

\section{ACKNOWLEDGMENTS}

A portion of this study was supported by the Oklahoma Department of Transportation (ODOT SP\&R Item Number 2231). Additional support was provided by the Structural Engineering and Materials Laboratory of the Infrastructure Research Institute at the University of Kansas.

\section{REFERENCES}

ASCE, 2013a, Report Card for America's Infrastructure, American Society of Civil Engineers, Reston, VA, 119 pp.

ASCE, 2013b, Failure to Act: The Impact of Current Infrastructure Investment on America's Economic Future, American Society of Civil Engineers, Reston, VA, 25 pp.

ASTM A955/A955M-15, 2015, "Standard Specification for Plain and Deformed Stainless-Steel Bars for Concrete Reinforcement," ASTM International, West Conshohocken, PA, $11 \mathrm{pp}$.

Darwin, D.; O’Reilly, M.; Somogie, I.; Sperry, J.; Lafikes, J.; Storm, S.; and Browning, J., 2013, "Stainless Steel Reinforcement as a Replacement for Epoxy Coated Steel in Bridge Decks," Final Project Report - FHWAOK-13-08, Oklahoma Department of Transportation, Aug., 205 pp., also SM Report No. 105, Univ. of Kansas Center for Research, Lawrence, KS.

Ji, J.; Darwin, D.; and Browning, J. P., 2005, "Corrosion Resistance of Duplex Stainless Steels and MMFX Microcomposite Steel for Reinforced Concrete Bridge Decks," SM Report No. 80, University of Kansas Center for Research, Lawrence, KS, 507 pp.

Jones, D., 1996, Principles and Prevention of Corrosion, Prentice Hall, Upper Saddle River, NJ, 572 pp.

Koch, G.; Broongers, H.; Thompson, N.; Virmani, Y.; and Payer, J., 2002, "Corrosion Cost and Preventive Strategies in the United States," Report No. FHWA-RD-01-156, Federal Highway Administration, McLean, VA, $773 \mathrm{pp}$.

McDonald, D.; Sherman, M.; Pfeifer, D.; and Virmani, P., 1995, "Stainless Steel Reinforcing as Corrosion Protection," Concrete International, V. 17, No. 5, May, pp. 65-70.

O'Reilly, M.; Darwin, D.; Browning, J. P.; and Locke, C. E., 2011, "Evaluation of Multiple Corrosion Protection Systems for Reinforced Concrete Bridge Decks," SM Report No. 100, University of Kansas Center for Research, Lawrence, KS, $535 \mathrm{pp}$.

Smith, F., and Tullmin, M., 2007, "Using Stainless Steels as LongLasting Rebar Material," Materials Performance, V. 38, No. 5, pp. 72-76.

Trejo, D., and Pillai, R., 2004, "Accelerated Chloride Threshold-Part II: Corrosion-Resistant Reinforcement," ACI Materials Journal, V. 101, No. 1, Jan.-Feb., pp. 57-64. 